\title{
An indirect pro-environmental behavior: public support for waste management policy
}

\section{Introduction}

Policy support (PS) can be considered as a form of non-activist environmental behavior or an indirect pro-environmental behavior (PEB) that individuals positively contribute to the environment by showing support to environmental policies (Stern, 2000). It can be presented in various forms, either positive or negative, including but not limited to signing petitions, voting for an issue, NIMBY mindset, willing to pay higher taxes or to endorse more resources for environmental protection, showing approval of environmental regulations, or following instructions given by environmental policies. Therefore, PS can be reinterpreted as an individual's favorable attitude toward a policy, which overt or covert actions may be taken place that make a profound impact on environmental protection.

Gaining PS for waste management policy (WMP) is of critical importance, particularly when the public authority emphasizes on recycling, reduction, reuse, and recovery (4Rs). The 4Rs require citizens' changes in consumption preferences; thereby public support has become a prerequisite for effective policy enactment and implementation. People possessing a high level of PS are prone to comply with policies and accept institutional directives. Insufficient PS, by contrast, is a barrier to instituting environmental policy in a smooth way, and the policy may end in failure. Adequate PS has substantial impacts on policy performance and goal achievement. To maximize PS, the authority should understand driving forces and mechanisms of forming positive policy attitudes. Current literature offers explanations of PS for WMP from socio-psychological and 
political perspectives. This editorial reviews these factors (Fig. 1) and discusses the importance of maximizing PS for WMP from both perspectives.

\section{Socio-psychological factors influencing policy support}

There are five socio-psychological factors that influence level of PS for waste management policy (Wan, Shen, \& Yu, 2015).

- Attitude. It refers to whether an individual favors or disfavors a specific behavior. For example, if an individual carries a positive attitude toward recycling, s/he will increase the likelihood of performing recycling behaviors and to support for policy measures that encourage such behaviors. Attitude is a multi-dimensional construct that comprises experiential (i.e., favor or disfavor a behavior) and instrumental (i.e., perceived outcomes of performing a behavior) components. Prior studies defined and measured attitude in terms of the experiential component only; however, increasing literature has proved instrumental component also plays role in influencing behaviors.

- Cost and benefits. Similar to the notion of economic rationality, people evaluate costs and benefits before performing a behavior. For instance, if an individual perceives the 4Rs would cause desirable outcomes such as preserving natural resources, reducing landfill burden, s/he tends to support policies that drive these behaviors.

- Social influences. Influences from others guide and govern our behaviors. The influences derive from various sources, including important others of individuals (e.g., family members and peers), mass media and environmental groups. Adherence to others' expectations people 
can gain social approval. Accordingly, people who perceive strong social influences supporting WMP are more likely to form a favorable attitude toward the policies.

- Past behavior. Past experience may help people overcome difficulties in performing a certain type of behavior. Also, people with experience of engaging in these behaviors would likely to generate an automatic reaction in similar situations. Therefore, pro-environmental programs such as reusing materials or mandatory recycling would not cause additional burdens on individuals who have already been participating in PEBs. In this connection, individuals will tend to support the policies.

- Place attachment. It is individuals' psychological feeling of being attached to a specific place. A strong sense of place attachment will drive individuals' proximity-maintaining behaviors, i.e., to protect the environment of a place that psychologically attached. If an individual attaches himself or herself to a particular city or country, s/he will be liable to support policies on environmental protection.

\section{Political factors influencing policy support}

A growing number of studies have investigated PS by resorting to political explanations (Matti, 2015). Five political factors were identified from literature of environmental studies.

- Perceived policy effectiveness. People are prone to support a policy if they perceive that it is effective for achieving intended outcomes. Such perception is termed as perceived policy effectiveness that refers to citizens' beliefs in the public authority for its competence 
in effective achievement of policy goals. An effective policy increases the attractiveness of PEBs, and motivates people to support for and comply with the policy.

- Political trust. It refers to citizens' level of confidence that the government will produce outcomes which are consistent with their expectations. A trustworthy government can engender public's willingness to comply with laws, to support government initiatives, and to follow political leadership without needing to be coerced. Insufficient trust in the government and politicians is the root cause of people's reluctance to support for environmental policies.

- Fairness. In all cases individuals bear a certain degree of burden for a better environment, either in terms of financial cost or non-financial sacrifice; thus, they pay a considerable attention to the ways policy decisions are made and outcomes that might affect them. First, the public are concerned about if all stakeholders are treated consistently and respectfully, and whether their opinions are well considered during the policy formulation processes. Second, policy outcomes should be fair in a sense that every member of the society bears the cost by fair principles (e.g., Pay-As-You-Throw program is an example of fair policy which it is formed according to "polluter-pays principle"). These two aspects form individuals' perceived justice of a policy that subsequently shapes level of PS.

- Policy preference. Environmental policy has to fight for resources with other policies such as economic measures. Given limited resources and political considerations, the government would only give priority to some policies. However, the public may express a preference for environmental policies that have not been set on the policy agenda. The policy preference gap may result in deficit of policy support. In other words, whether policy-makers have taking public preferences seriously would affect the level of PS. 
- Participatory process. Engaging the public in policy formulation processes helps recruit PS, and in return, contributes to the success of policy. An ideal practice should be granting people an early participatory process for policy formulation. Not only it allows policymakers to grasp public opinions and formulate a responsive policy but also accumulates PS for the policy.

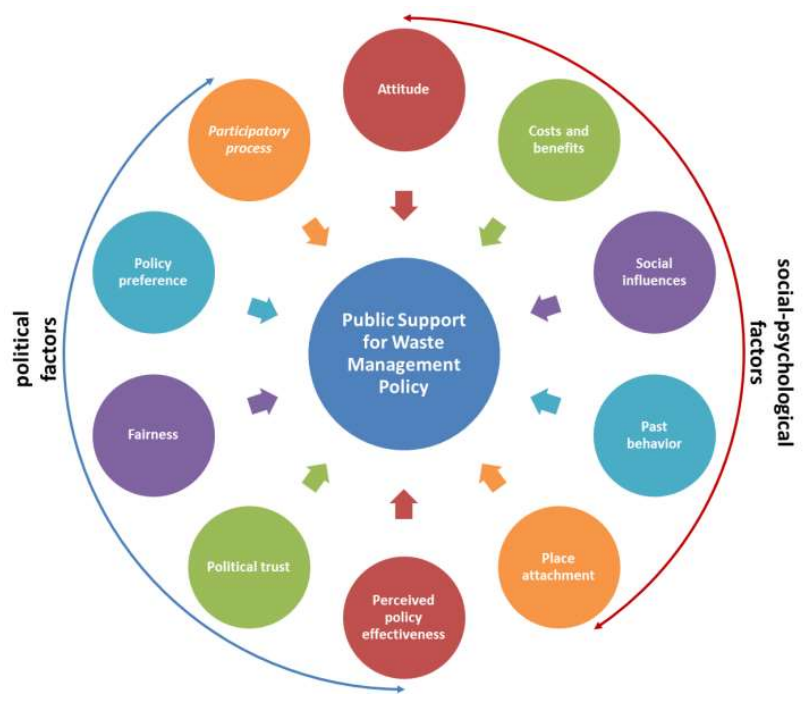

Fig. 1. The socio-psychological and political factors influencing policy support

\section{Strategies to maximizing public support for WMP}

To gain PS from the socio-psychological perspective, the public authority can launch promotional campaigns to enhance people's attitudes, perceived benefits, external influences, and place attachment. Attitudes toward PEBs and perceived benefits can be improved by promoting positive environmental outcomes of the 4Rs behaviors. With an emphasis on the popularity of these behaviors in the society or being delivered by celebrities, promotional messages would 
increase perception of external influences. To strengthen the sense of place attachment, the government may make use of emotional messages highlighting the importance of city/country to people as part of their home/history. Besides, organizing social activities such as recycling program and clean-up program that engage residents to improve the environment collectively can enhance perceived place ownership.

Politically, holding effective public hearing and public consultation is a possible way to enhance both political trust and fairness of the policy, as well as to address the need of public involvement. The exercise improves the governance by having greater transparency of and engaging the public and stakeholders to participate in policy formulation processes. It ensures citizens' opinions and suggestions would be well considered, and their preferences are included for agenda setting. The practice can project a fair perception because it allows expression of public opinions and takes different parties' concerns into account. Moreover, adequate soft measures (e.g., recycling guidelines) and hard measures (e.g., recycling bins) can boost public's confidence in policy effectiveness. The affirmative perception encourages citizens to support for WMP.

\section{Concluding remarks}

Previous studies have identified socio-psychological and political factors influencing the public's policy support. However, most of these studies focused on investigating single factor, and lack an integrated perspective for analysis. This editorial systematically reviewed these 
factors that offer a more comprehensive explanation of public support for waste management and other environmental policies.

\section{Acknowledgements}

The information in this editorial forms part of a research project fully supported by a grant from the Research Grants Council of the Hong Kong Special Administrative Region (Project Ref. No.: UGC/FDS24/H02/15).

\section{References}

Matti, S. (2015). Climate Policy Instruments. In K. Bäckstrand \& E. Lövbrand (Eds.), Research Handbook of Climate Governance (pp. 400-410). Cheltenham: Edward Elgar Publishing.

Stern, P. C. (2000). New environmental theories: toward a coherent theory of environmentally significant behavior. Journal of Social Issues, 56(3), 407-424.

Wan, C., Shen, G. Q., \& Yu, A. (2015). Key determinants of willingness to support policy measures on recycling: A case study in Hong Kong. Environmental Science \& Policy, 54, 409-418.

C. Wan

S. Choi

School of Professional Education and Executive Development, The Hong Kong Polytechnic University, Hung Hom, Hong Kong E-mail address: spcalvin@speed-polyu.edu.hk(C. Wan) E-mail address:wffchoi@speed-polyu.edu.hk(S. Choi)

G. Shen

Department of Building and Real Estate, The Hong Kong Polytechnic University, Hung Hom, Hong Kong E-mail address: geoffrey.shen@polyu.edu.hk 